\title{
Flavonoid and Diterpenoid Components from Teucrium orientale subsp. orientale and their Radical Scavenging Activity
}

\author{
Melika Alviri $^{1}{ }^{(\mathbb{D}}$, Mir Babak Bahadori ${ }^{2, *}{ }^{\mathbb{D}}$, Shahram Bahadori ${ }^{3(\mathbb{D})}$ \\ 1 Department of Pharmacognosy, Faculty of Pharmacy, Urmia University of Medical Sciences, Urmia, Iran; \\ alviri.melika@yahoo.com (M.A.); \\ 2 Medicinal Plants Research Center, Maragheh University of Medical Sciences, Maragheh, Iran; mb.bahadori@gmail.com \\ (M.B.B.); \\ 3 Department of Biology, Faculty of Basic Sciences, University of Tehran; shahrambahadori28@ yahoo.com (S.B.); \\ * Correspondence: mb.bahadori@gmail.com;
}

Scopus Author ID 57217797462

Received: 15.03.2021; Revised: 12.04.2021; Accepted: 15.04.2021; Published: 26.04.2021

\begin{abstract}
Being a member of the Lamiaceae family, Teucrium orientale (named Maryam Nokhodi in Iran) grows in Iran, Turkey, Iraq, Caucasus, Syria, Lebanon, Afghanistan, Pakistan, Turkmenistan, Central Asia, Europe, and North Africa. Among the pharmacological effects, Teucrium orientale is confirmed to have antidiabetic, antihemorrhoidal, antidysmenorrhea, antioxidant, antipyretic, antibacterial, anticandidal, and pesticide effects. The genus Teucrium comprises many bioactive compounds, including flavonoids, monoterpenes, sesquiterpenes, diterpenoids, phenolic acids, and fatty acid esters. In this work, in order to investigate the phytochemistry of Teucrium orientale, the aerial parts of the plant were extracted by maceration. The column chromatography technique was used to fractionate the acetonic extract. Purified compounds were obtained by smaller chromatography columns and techniques, including preparative thin layer chromatography, precipitation, and recrystallization. Chemical structures of compounds were identified by NMR and FT-IR spectroscopy and also elemental analysis. The compounds were elucidated as sclareol, quercetin, and luteolin. Furthermore, the antioxidant activity of the isolated compounds was evaluated.
\end{abstract}

Keywords: Teucrium; Diterpenoid; Flavonoid; Pharmacognosy; Antioxidant

(C) 2021 by the authors. This article is an open-access article distributed under the terms and conditions of the Creative Commons Attribution (CC BY) license (https://creativecommons.org/licenses/by/4.0/).

\section{Introduction}

Being a member of the Lamiaceae family, the genus Teucrium comprises approximately 300 species worldwide [1] and 12 species distributed in Iran, which include $T$. macrum and T. persicum exclusively grow in Iran [2]. Other species are as follows: T. orientale, T. oliverianum, T. procerum, T. parviflorum, T. hircanicum, T. scordium, T. melissoides, $T$. chamaedrys, T. polium, and T. stocksianum, which grow in Iran, Turkey, Iraq, the Caucasus, Syria, Lebanon, Afghanistan, Pakistan, Turkmenistan, Central Asia, Europe, and North Africa.

In herbal medicine, Teucrium species are utilized to cure many pathological conditions such as diabetes, wounds, fever, insomnia, neurological disorders, abdominal cramps, gastrointestinal disorders, cold, hypertension, diarrhea, stomachache, inflammation, and rheumatism [3].

The pharmacological experiments approve many of the effects mentioned above. Moreover, the genus is confirmed to have antioxidant, anti-inflammatory, DNA protective, 
antinociceptive, cytotoxic, insulinotropic and antidiabetic, hepatoprotective, antiulcerogenic, antidiarrheal, anti hemorrhoid, antimicrobial, antiparasitic, and antifeedant properties [4-8].

The genus Teucrium is rich in flavonoids, sesquiterpenes, abietane, clerodane, and neoclerodane diterpenoids, phenolic acids, and fatty acids [9-12]. Also, essential oils with monoterpenes and sesquiterpenes as main components are volatile components of Teucrium species [13-15].

Teucrium orientale, locally named "Maryam Nokhodi" in Iran, is traditionally used as an antidiabetic, antipyretic, and anti hemorrhoidal agent. Furthermore, it is believed that this plant is effective in reducing menstrual pain. It is also known to be beneficial in healing wounds and skin injuries [16].

Phytochemical investigations have shown that Teucrium orientale comprises many bioactive compounds, including flavonoids, iridoids, neoclerodane diterpenoids, and phenolic acids [17], as well as containing monoterpenes and sesquiterpenes as the major components of the essential oil $[17,18]$. This study aimed to purify and characterize the bioactive constituents of acetone extract of $T$. orientale subsp. orientale and evaluate their antioxidant ability.

\section{Materials and Methods}

\subsection{Chemicals.}

Being purchased from Merck (Germany), the reagents were used without further purification. Organic solvents were purchased as follows: Acetone, ethyl acetate, pyridine, and sulfuric acid from Carlo Erba. Chloroform, dichloromethane ethanol, hexane, and methanol from Dae-Jung.

\subsection{Plant material.}

Arial parts of $T$. orientale were collected in summer 2015 at the flowering stage from Ghasemlou Valley, Urmia, West Azerbaijan province, Iran. The taxonomist made botanical identification of Urmia Faculty of Pharmacy. A herbarium specimen (HUPS-2) has been deposited in the Herbarium of the Faculty of Pharmacy, Urmia University of Medical Sciences, Urmia, Iran.

\subsection{Extraction and isolation.}

Air-dried aerial parts of $T$. orientale $(700 \mathrm{~g})$ were macerated for $72 \mathrm{~h}$ by acetone and then the extract was filtered. The same procedure was carried out in triplicate for the residue. The acetone extract was concentrated to dryness using a rotary evaporator. The methanolic extract was obtained from the residue through the procedure mentioned above.

The column chromatography technique was used to fractionate the acetone extract. Twenty-nine grams of dried extract were fractionated by a one-meter high column, filled with $300 \mathrm{~g}$ silica gel $60(0.063-0.200 \mathrm{~mm})$ as the stationary phase and $500 \mathrm{~mL}$ hexane as the mobile phase. Gradient elution was performed with ascending ratios of ethyl acetate in hexane. Samples were collected every $200 \mathrm{~mL}$ or after the color change of outlet solution and were concentrated by rotary evaporator. TLC analyses were performed for each concentrated sample, and identical samples were combined according to TLC results. Finally, 19 fractions (F1-F19) were obtained. 
F16 was dissolved in $15 \mathrm{~mL}$ methanol and $15 \mathrm{~mL}$ chloroform. After precipitation, the precipitate was washed with methanol and turned to white. The sample was white sediment named compound 1 (9 mg).

To purify the plant's biochemical compounds, F4, F14 and a combination of F7 and F8 were selected due to their quantity and TLC results and were purified by smaller chromatography columns and techniques, including preparative thin layer chromatography (Preparative TLC or plates) and recrystallization.

Three fractions (F14-1, F14-2, and F14-3) obtained from column chromatography of main fraction F14, were combined and undergone multiple recrystallizations for further purification. A light yellow solid was obtained and named compound 2 (17 mg).

Fraction F14-18, also obtained from column chromatography of main fraction F14, contained some yellowish sediment. The sediment was washed with acetone to remove impurities. The yellow sediment was named compound 3 (24 mg).

\subsection{NMR experiments.}

To obtain ${ }^{1} \mathrm{H}$ and ${ }^{13} \mathrm{C}$ NMR spectra, Bruker Avance $400 \mathrm{MHz}$ spectrometer (operated at $400 \mathrm{MHz}$ and $100 \mathrm{MHz}$, respectively) was employed. The deuterated solvents were $\mathrm{CDCl}_{3}$ and DMSO- $d_{6}$ and the internal standard was TMS in these experiments.

\subsection{FT-IR analysis.}

IR spectra were recorded on a Shimadzu FTIR-8400S spectrophotometer, and $\mathrm{KBr}$ pellets were used as a carrier for the samples.

\subsection{Melting point.}

Measurement of the melting points was carried out in open glass capillaries and taken by the electrothermal melting point apparatus.

\subsection{Elemental analysis.}

Costech elemental analyzer was utilized to perform the elemental analysis for $\mathrm{C}, \mathrm{H}$, and $\mathrm{N}$ atoms.

\subsection{Antioxidant activity assessment.}

Purified compounds were dissolved in methanol to make various concentrations (7.8$500 \mu \mathrm{g} / \mathrm{mL}$ ). A concentration of $80 \mu \mathrm{g} / \mathrm{mL}$ of DPPH (the substance used to evaluate the antioxidant activity) was prepared by dissolving $8 \mathrm{mg}$ of DPPH in methanol. One $\mathrm{mL}$ of diluted solutions were separately added to a $1 \mathrm{~mL}$ solution of DPPH and left for $30 \mathrm{~min}$ due to the reaction to be completed. Also, the same steps were repeated for the reference compound, rutin. The UV absorbance of samples was recorded at $517 \mathrm{~nm}$. The assays were made three times, and the average absorption was calculated for each concentration [19].

\section{Results and Discussion}

Three natural compounds were purified from the acetonic extract of the aerial parts of T. orientale (Figure 1). Their chemical structure was elucidated as sclareol (1), quercetin (2), 
and luteolin (3) based on spectroscopic analysis (NMR and FT-IR) and comparison with those reported in the literature.

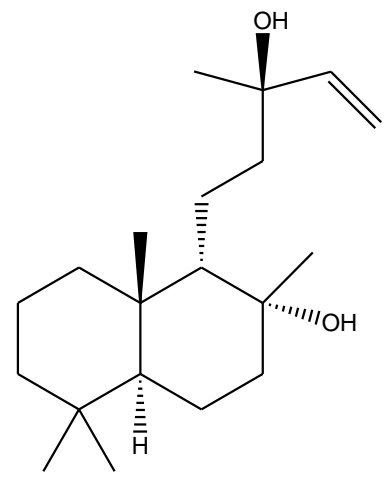

Sclareol<smiles>O=c1cc(-c2ccc(O)c(O)c2)oc2cc(O)cc(O)c12</smiles><smiles>O=c1c(O)c(-c2ccc(O)c(O)c2)oc2cc(O)cc(O)c12</smiles>

Figure 1. Chemical structure of isolated compounds from T. orientale.

Compound 1 (sclareol) was obtained as a white powder and is reported from the genus Teucrium's extracts for the first time (Figure 2). It was isolated from the Salvia species (Lamiaceae family) before. Sclareol belongs to labdane diterpenoids with molecular formula $\mathrm{C}_{20} \mathrm{H}_{36} \mathrm{O}_{2}$. It was found to have antiproliferative activity against cancerous cells and also anticholinesterases effect [20].

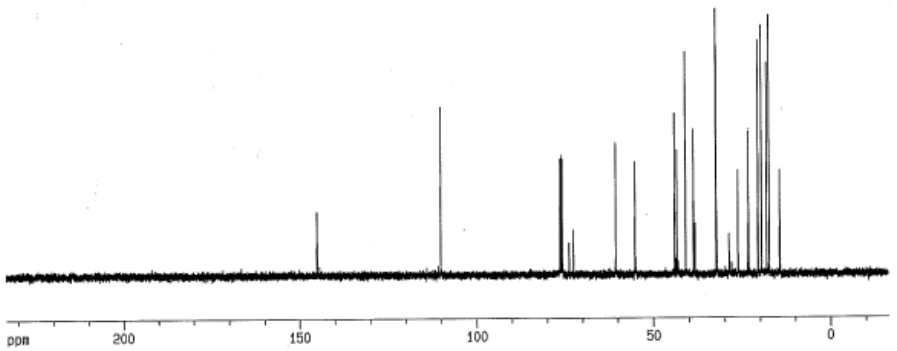

Figure 2. ${ }^{13} \mathrm{C}-\mathrm{NMR}$ of sclareol in $\mathrm{CDCl}_{3}$ at $100 \mathrm{MHz}$. 
Compound 2 (quercetin) was obtained as a yellowish powder (Figure 3). Quercetin belongs to flavonols from the large class of natural product flavonoids. It is a common flavonoid compound in medicinal plants, vegetables, wine, and fruits [21]. Quercetin has been reported from different Teucrium species. It is consumed as a dietary supplement. Moreover, quercetin has great pharmacological properties, including antioxidant, anti-inflammatory, and protein kinase inhibitory activity [22].

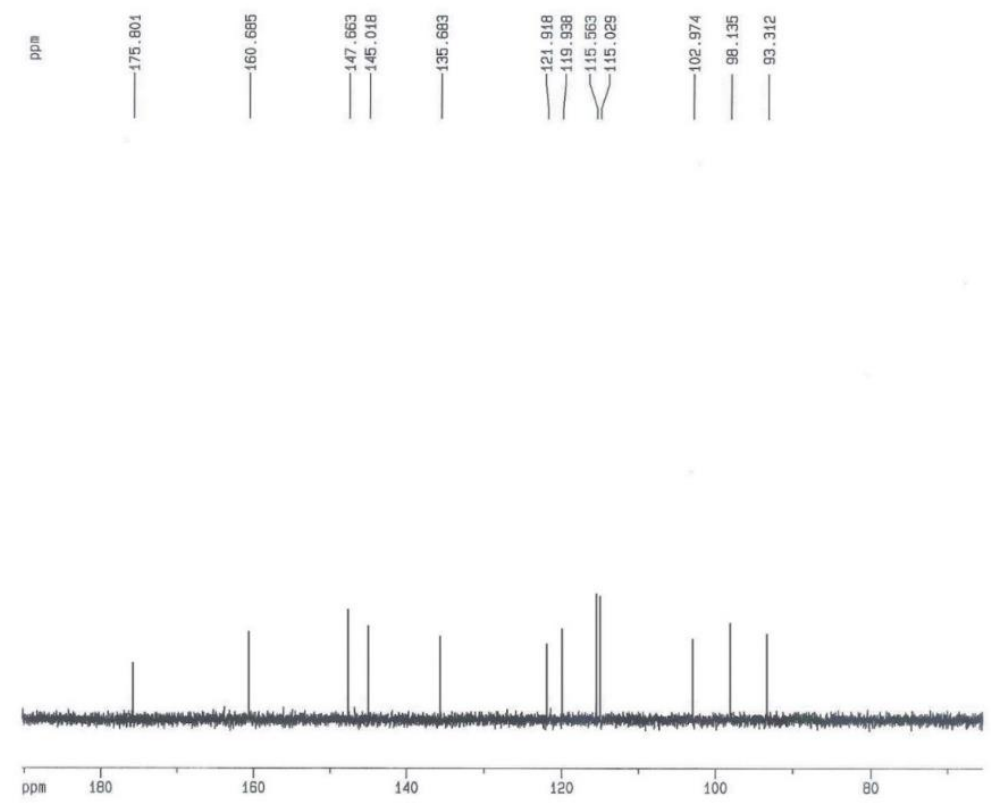

Figure 3. ${ }^{13} \mathrm{C}-\mathrm{NMR}$ of quercetin in DMSO-d6 at $100 \mathrm{MHz}$.

Compound 3 (luteolin) was purified as an amorphous yellowish solid (Figure 4). Luteolin is a flavone naturally occurring in medicinal foods such as rosemary, sage, peppermint, olive oil, and carrot. It was also previously reported from the genus Teucrium. Luteolin has important biological activities, including anticancer, anti-inflammatory, antimicrobial, and anti-Alzheimer's disease [23].
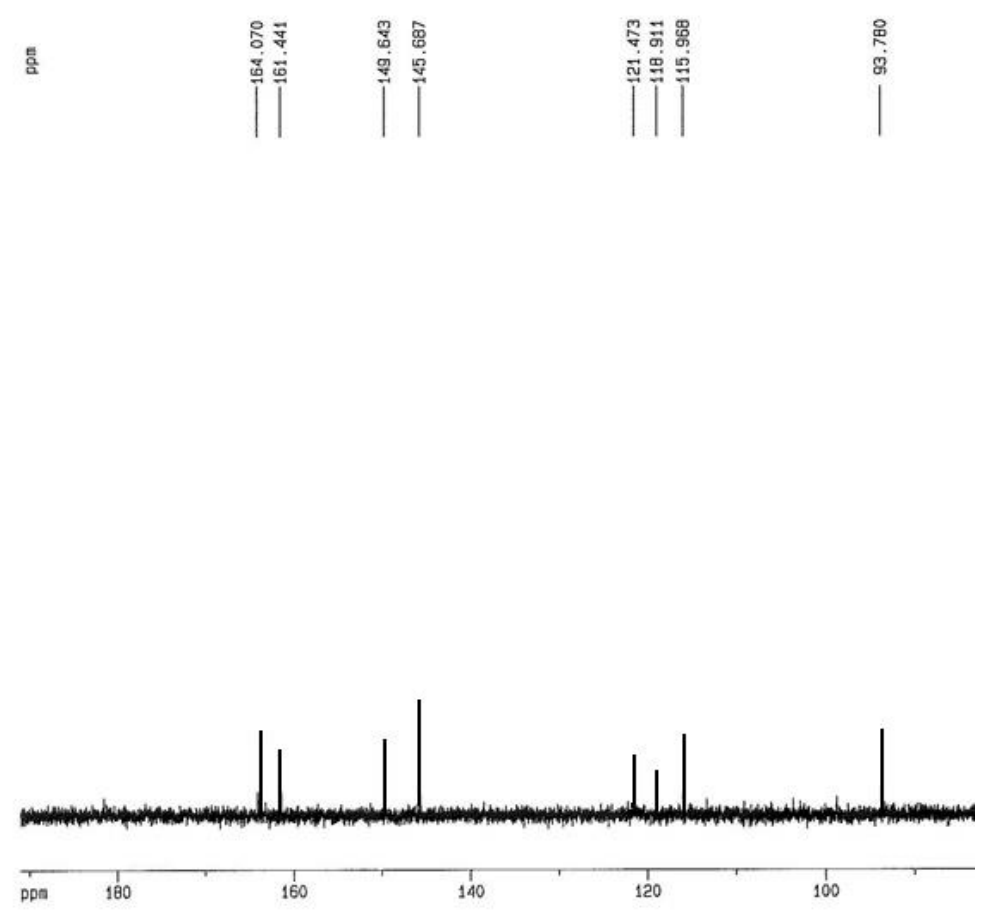

Figure 4. ${ }^{13} \mathrm{C}-\mathrm{NMR}$ of luteolin in DMSO-d 6 at $100 \mathrm{MHz}$. 
In this study, the DPPH radical scavenging ability of the isolated compounds was evaluated. In this direction, different concentrations of the samples were used for the measurement of radical scavenging activity. Rutin was used as a standard antioxidant agent. As could be seen from Table 1, quercetin with $\mathrm{IC}_{50}$ value of $17.7 \pm 1.2 \mu \mathrm{g} / \mathrm{mL}$ showed the strongest antiradical activity followed by luteolin $(18.6 \pm 1.9 \mu \mathrm{g} / \mathrm{mL})$. Sclareol exerted a mild antioxidant activity.

Table 1. Antioxidant activity of isolated compounds from T. orientale.

\begin{tabular}{c|c} 
Compound & IC $_{\mathbf{5 0}}(\boldsymbol{\mu g} / \mathbf{m L})$ \\
\hline Sclareol & $129.3 \pm 11.8$ \\
\hline Quercetin & $17.7 \pm 1.2$ \\
\hline Luteolin & $18.6 \pm 1.9$ \\
\hline Rutin (standard) & $22.1 \pm 1.6$
\end{tabular}

\section{Conclusions}

Teucrium orientale (Lamiaceae) was phytochemically investigated. Chromatographic techniques were employed for the separation of bioactive components. Diterpenoid and flavonoid metabolites were purified from acetone extract of the plant. NMR, FT-IR, and elemental analysis were used for the structure elucidation of pure compounds. Sclareol, quercetin, and luteolin showed moderate to high radical scavenging activity. Results indicate that $T$. orientale could be considered as an important source of biologically active natural products.

\section{Funding}

This study was supported by the Faculty of Pharmacy, Urmia University of Medical Sciences (Thesis Code: 35).

\section{Acknowledgments}

The authors thank Maragheh University of Medical Sciences for its technical support.

\section{Conflicts of Interest}

The authors declare no conflict of interest.

\section{References}

1. Candela, R. G.; Rosselli, S.; Bruno, M.Fontana, G. A Review of the phytochemistry, traditional uses and biological activities of the essential oils of genus Teucrium. Planta Med 2020, https://doi.org/10.1055/a-12935768.

2. Rahimi, M. A.; Nazeri, V.; Andi, S. A.Sefidkon, F. Variation in essential oil composition of Teucrium hircanicum L. from Iran-A rich source of (E)- $\alpha$-bergamotene. Nat Prod Res 2019, 33, 1227-1232, https://doi.org/10.1080/14786419.2018.1466122.

3. Asghari, A. A.; Mokhtari-Zaer, A.; Niazmand, S.; Mc Entee, K.Mahmoudabady, M. Anti-diabetic properties and bioactive compounds of Teucrium polium L. Asian Pacific Journal of Tropical Biomedicine 2020, 10, 433.

4. Noumi, E.; Snoussi, M.; Anouar, E. H.; Alreshidi, M.; Veettil, V. N.; Elkahoui, S.; Adnan, M.; Patel, M.; Kadri, A.; Aouadi, K.; De Feo, V.; Badraoui, R. HR-LCMS-Based metabolite profiling, antioxidant, and anticancer properties of Teucrium polium L. methanolic extract: Computational and in vitro study. Antioxidants 2020, 9, 1089, . 
5. Alreshidi, M.; Noumi, E.; Bouslama, L.; Ceylan, O.; Veettil, V. N.; Adnan, M.; Danciu, C.; Elkahoui, S.; Badraoui, R.; Al-Motair, K. A.; Patel, M.; De Feo, V.; Snoussi, M. Phytochemical screening, antibacterial, antifungal, antiviral, cytotoxic, and anti-quorum-sensing properties of Teucrium polium $\mathrm{L}$ aerial parts methanolic extract. Plants 2020, 9, 1418, https://doi.org/10.3390/plants9111418.

6. Aydoğan, F.; Anouar, E.; Aygün, M.; Yusufoglu, H.; Karaalp, C.Bedir, E. An unprecedented diterpene with three new neoclerodanes from Teucrium sandrasicum O. Schwarz. J Mol Struct 2021, 1231, 129919, https://doi.org/10.1016/j.molstruc.2021.129919.

7. Al-Hamwi, M.; Aboul-Ela, M.; El-Lakany, A.Nasreddine, S. Anticancer activity of Micromeria fruticosa and Teucrium polium growing in Lebanon. Pharmacognosy Journal 2021, 13, https://doi.org/10.5530/pj.2021.13.15.

8. Marković, A.; Tubić Vukajlović, J.; Grujičić, D.; Radović Jakovljević, M.; Stanković, M.; Djordjević, K.; Djelić, N.; Radaković, M.Milošević-Djordjević, O. Methanol extracts of Teucrium arduini L. and Teucrium flavum L. induce protective effect against mitomycin C in human lymphocytes in vitro. Drug Chem Toxicol 2020, 1-7, https://doi.org/10.1080/01480545.2020.1802477.

9. Rizvi, T.; Hussain, I.; Ali, L.; Mabood, F.; Khan, A.; Shujah, S.; Rehman, N.; Al-Harrasi, A.; Hussain, J.: Khan, A.Halim, S. A. New gorgonane sesquiterpenoid from Teucrium mascatense Boiss, as $\alpha$-glucosidase inhibitor. S Afr J Bot 2019, 124, 218-222, https://doi.org/10.1016/j.sajb.2019.05.008.

10. Grujičić, D.; Marković, A.; Vukajlović, J. T.; Stanković, M.; Jakovljević, M. R.; Ćirić, A.; Djordjević, K.; Planojević, N.; Milutinović, M.Milošević-Djordjević, O. Genotoxic and cytotoxic properties of two medical plants (Teucrium arduini L. and Teucrium flavum L.) in relation to their polyphenolic contents. Mutation Research/Genetic Toxicology and Environmental Mutagenesis 2020, 852, 503168, https://doi.org/10.1016/j.mrgentox.2020.503168.

11. Kaska, A.; Çiçek, M.Mammadov, R. Biological activities, phenolic constituents and mineral element analysis of two endemic medicinal plants from Turkey: Nepeta italica subsp. cadmea and Teucrium sandrasicum. S Afr J Bot 2019, 124, 63-70, https://doi.org/10.1016/j.sajb.2019.04.037.

12. Fois, B.; Corona, A.; Tramontano, E.; Distinto, S.; Maccioni, E.; Meleddu, R.; Caboni, P.; Floris, C.Cottiglia, F. Flavonoids and Acid-Hydrolysis derivatives of Neo-Clerodane diterpenes from Teucrium flavum subsp. glaucum as inhibitors of the HIV-1 reverse transcriptase-associated RNase H function. J Enzyme Inhib Med Chem 2021, 36, 749-757, https://doi.org/10.1080/14756366.2021.1887170.

13. Pavela, R.; Benelli, G.; Canale, A.; Maggi, F.Mártonfi, P. Exploring essential oils of Slovak medicinal plants for insecticidal activity: The case of Thymus alternans and Teucrium montanum subsp. jailae. Food Chem Toxicol 2020, 138, 111203, https://doi.org/10.1016/j.fct.2020.111203.

14. Znini, M.; Costa, J.Majidi, L. Chemical constituents of the essential oil of endemic Teucrium luteum subsp. flavovirens (batt.) Greuter \& burdet collected from two localities in Morocco. Journal of Essential Oil Research 2020, 1-7, https://doi.org/10.1080/10412905.2020.1857853.

15. Maccioni, A.; Falconieri, D.; Porcedda, S.; Piras, A.; Gonçalves, M. J.; Alves-Silva, J. M.; Salgueiro, L.Maxia, A. Antifungal activity and chemical composition of the essential oil from the aerial parts of two new Teucrium capitatum L. chemotypes from Sardinia Island, Italy. Nat Prod Res 2020, 1-7, https://doi.org/10.1080/14786419.2020.1813136.

16. Moghadam, H. B.Kharazian, N. Morphologic and chemotaxonomic studies of some Teucrium L.(Lamiaceae) in Zagros region, Iran. Iranian Journal of Science and Technology, Transactions A: Science 2020, 44, 933953, https://doi.org/10.1007/s40995-020-00908-1.

17. Reaisi, Z.; Yadegari, M.Shirmardia, H. A. Effects of phenological stage and elevation on phytochemical characteristics of essential oil of Teucrium polium L. and Teucrium orientale L. International Journal of Horticultural Science and Technology 2019, 6, 89-99, https://doi.org/10.22059/IJHST.2019.275327.276.

18. Sonboli, A.; Bahadori, M. B.; Dehghan, H.; Aarabi, L.; Savehdroudi, P.; Nekuei, M.; Pournaghi, N.Mirzania, F. Chemotaxonomic importance of the essential-oil composition in two subspecies of Teucrium stocksianum Boiss. from Iran. Chem Biodiversity 2013, 10, 687-694, https://doi.org/10.1002/cbdv.201200088.

19. Zengin, G.; Atasagun, B.; Aumeeruddy, M. Z.; Saleem, H.; Mollica, A.; Bahadori, M. B.Mahomoodally, M. F. Phenolic profiling and in vitro biological properties of two Lamiaceae species (Salvia modesta and Thymus argaeus): A comprehensive evaluation. Industrial Crops and Products 2019, 128, 308-314, https://doi.org/10.1016/j.indcrop.2018.11.027.

20. Ravera, S.; Esposito, A.; Degan, P.; Caicci, F.; Calzia, D.; Perrotta, E.; Manni, L.; Bisio, A.; Iobbi, V.; Schito, A.; Traverso, C. E.Panfoli, I. Sclareol modulates free radical production in the retinal rod outer segment by 
inhibiting the ectopic f1fo-atp synthase. Free Radic Biol Med 2020, 160, 368-375, https://doi.org/10.1016/j.freeradbiomed.2020.08.014.

21. Tang, S.-M.; Deng, X.-T.; Zhou, J.; Li, Q.-P.; Ge, X.-X.Miao, L. Pharmacological basis and new insights of quercetin action in respect to its anticancer effects. Biomed Pharmacother 2020, 121, 109604, https://doi.org/10.1016/j.biopha.2019.109604.

22. Batiha, G. E.-S.; Beshbishy, A. M.; Ikram, M.; Mulla, Z. S.; El-Hack, M. E. A.; Taha, A. E.; Algammal, A. M.Elewa, Y. H. A. The pharmacological activity, biochemical properties, and pharmacokinetics of the major natural polyphenolic flavonoid: Quercetin. Foods 2020, 9, 374, https://doi.org/10.3390/foods9030374.

23. Potočnjak, I.; Šimić, L.; Gobin, I.; Vukelić, I.Domitrović, R. Antitumor activity of luteolin in human colon cancer SW620 cells is mediated by the ERK/FOXO3a signaling pathway. Toxicol In Vitro 2020, 66, 104852, https://doi.org/10.1016/j.tiv.2020.104852. 